\title{
LUNETAS MÁGICAS - TRADUÇÕES ÓTICAS EM MACEDO E ALENCAR
}

\author{
Guilherme Sarmiento $^{1}$
}

\begin{abstract}
Resumo: Através da análise de dois textos produzidos no século XIX - o foIhetim Ao correr de pena, de José de Alencar, e o romance A luneta mágica, de Joaquim Manuel de Macedo -, ilustram-se as inquietações geradas pelo encontro do olhar romântico com o mundo mediado pelas invenções óticas. Palavras-Chave: Invenções óticas; Representações literárias; Romantismo.
\end{abstract}

Resumen: A través del análisis de dos textos escritos en el siglo XIX - Ao correr da pena, de José de Alencar, y la novela $A$ luneta mágica, de Joaquim Manuel de Macedo - el artículo muestra las ansiedades generadas por el encuentro de la mirada romántica con el mundo mediado por las invenciones ópticas.

Palabras Clave: Invenciones ópticas; Representaciónes literárias; Romantismo.

Não sabemos se Joaquim Manuel de Macedo realmente leu o folhetim Ao correr da pena ${ }^{2}$ escrito por José de Alencar e publicado no Correio mercantil de 6 de maio de 1854. Neste ano, ele também estava na ativa, produzindo compulsivamente os capítulos de $O$ diário do meu tio, e só iria escrever os de $A$ luneta mágica quatorze anos depois ${ }^{3}$. Apesar de o tema já haver sido explorado por Frederico Soulié em suas Memórias do Diabo confessada pelo escritor cearense como uma das referências de sua crônica folhetinesca, possivelmente lida também por Macedo - as inúmeras coincidências existentes entre as obras dos romancistas brasileiros, a contemporaneidade entre os dois escritores, fazem de $A$ luneta mágica um romance-folhetim paródico, alegórico, cuja realização em nenhum momento exigiu do leitor algum reconhecimento por sua originalidade.

A primeira referência comum entre as obras de Alencar e Macedo, a que salta aos olhos, é a citação de um conhecido comerciante e fabricador

1 Doutor em Literatura Brasileira pela PUC-Rio, onde defendeu tese sobre fantasmagorias óticas na Corte Imperial; Professor Adjunto de Dramaturgia na Universidade Federal do Recôncavo da Bahia (UFRB); Líder do Núcleo de Pesquisa em Dramaturgia, grupo que pretende aprofundar a escrita cinematográfica, atua também como roteirista de longas e curtas metragens. Endereço eletrônico: guilhermesarmiento@predialnet.com.br.

2 ALENCAR, José de. Ao correr da pena. São Paulo: Melhoramentos, 1955, p. 9

3 MACEDO, Joaquim Manuel de. A luneta mágica. São Paulo: L\&PM Pocket, 2001. 
de produtos óticos da Corte, José Maria dos Reis - os dois escritos primam pela mistura indiscriminada de ficção e realidade.

Ao que tudo indica, para seus contemporâneos, Reis era bem mais do que uma personagem secundária de folhetim ${ }^{4}$. Como mostra o historiador Almir Pita Freitas Filho ${ }^{5}$, ele chegou ao Brasil na década de 1820, emigrado dos Açores, ganhando seus cobres no trabalho das ruas. Sua vida profissional nos dez anos posteriores ainda está para ser completamente reconstruída. Sabe-se que em 1837 abriu um negócio de pequeno porte, uma importadora de objetos de ótica, à qual, em 1854, na época de Ao correr da pena, já tinha se multiplicado em três oficinas artesanais, sendo uma delas de instrumentos científicos e outra de marcenaria. Reis tornou-se figura de suma importância para o desenvolvimento de uma tecnologia brasileira, sobretudo na confecção de instrumentos astronômicos, participando ativamente da vida política e social do Rio de Janeiro, então Capital do Império, entre as décadas de 1860 e meados de 1870 . Quando morreu, em primeiro de agosto de 1875, o espanhol José Hermida Pazos levou sua obra até a virada do século $X X$, quando o nome das oficinas foi aos poucos se retirando do cenário científico-cultural do país ${ }^{6}$.

Portanto, a celebridade a que chegou Reis e suas oficinas já na década de 1850 mereceram a atenção dada por José de Alencar em sua crônica. Ela começou de maneira retrospectiva, com o cronista narrador rememorando o momento em que saía de casa para visitar o "novo estabelecimento ótico do Reis", na Rua do Hospício, número 71. Segundo o cronista,

Tinham-me feito tantos elogios deste armazém, do seu arranjo e elegância, que assentei de julgá-lo pelos meus próprios olhos.

Não foi, porém, esta a única razão que excitou a minha curiosidade. O que principalmente me levava àquela casa era um sentimento egoísta, um desejo de míope ${ }^{7}$.

4 Outro romance da época que cita José Maria dos Reis é $O$ doutor Benignus, de Augusto Emílio Zaluar, publicado em 1875. O cientista homônimo levou consigo, numa expedição ao norte do país, "o telescópio de Salomão, que comprara na grande oficina de J. M. dos Reis" (ZALUAR, Augusto Emílio. Doutor Benignus. Rio de Janeiro: Ed. UFRJ, 1994, p. 1860).

5 FILHO, Almir Pita Freitas. As officinas e armazém d'óptica e istrumentos scientíficos de José Maria Reis e José Hermida Pazos (Negociantes, ilustrados e utilitários em prol do desenvolvimento da ciência no Brasil). Rio de Janeiro: Museu do Observatório Nacional/CNPq, 1986.

FILHO, op. cit., p. 1-4.

7 ALENCAR, Ao correr da pena, op. cit., p. 205.

114 Número temático: literatura e cinema. A Cor das Letras - UEFS, n. 11, 2010 
Simplício, protagonista de A luneta mágica, romance de Macedo, também foi levado até as oficinas por ser míope, "física e moralmente", como gostava de dizer ${ }^{8}$. Quando suas peripécias foram publicadas, em 1868 , o estabelecimento de Reis vinha embalado no prestígio das Grandes Exposições Universais, acumulando alguns prêmios em decorrência do bom acabamento de seus produtos ${ }^{9}$. Em 1861, na Primeira Exposição Nacional, destacou-se a "luneta imperial", oferecida pelo proprietário ao imperador, lavrada em ouro e com "lentes de cristais de Goiás" ${ }^{10}$. Macedo pareceu brincar explicitamente com o fato quando outro personagem - que surgiu em apoio aos augúrios de Simplício - disse que o governo havia encomendado o mais perfeito pince-nez político:

O Reis fez obra de mestre, um pince-nez que por um dos vidros deixava ler as lições do passado e pelo outro os perigos do futuro; mas o pince-nez não achou nariz de ministro que se ajeite e foi desprezado ${ }^{11}$.

Simplício ficou sabendo dos milagres de Reis através do "velho Nunes", que o apresentou como:

um representante do espírito do século: começou plebeu e já está nobre pela constância no trabalho e pelo encanto do progresso; não sei se o Reis tem si-

8 MACEDO, A luneta mágica, op. cit., p. 11.

9 Segundo Almir Pita Freitas Filho, "as diversas exposições realizadas durante o século XIX, além de cumprirem sua função ideológica de tornar a burguesia industrial conhecida, abriam espaço também para a presença de empresários de países não industrializados. Muitos destes expositores foram distinguidos com medalhas e prêmios especiais pelos juris internacionais, a exemplo de José Maria dos Reis e José Hermida Pazos [...] A presença e premiação de empresários originários de países não industrializados nos certames internacionais da indústria tinham diversos significados. Sua vitória era um incentivo à participação em novas competições, além de aumentar-lhes o prestígio em seus países de origem. Garantia também um aumento nas vendas, uma expansão em seus negócios, pois eram sinais de qualidade, de credibilidade, para seus produtos. Este aspecto era bastante explorado pelos expositores, que, por muito tempo, utilizavam-no como efeito publicitário, pois significava que seus produtos eram comparáveis e até mesmo superiores aos estrangeiros, conferindo ao empresário-artífice uma elevada dose de orgulho para com os mesmos" (FILHO, op. cit., p. 16).

Joaquim Manuel de Macedo, na Exposição Nacional de 1873, iria fazer parte do júri que conferiria ao "Azimuthal", aparelho astronômico realizados nas oficinas de ótica do comerciante português, o prêmio de primeira classe daquele ano (FILHO, op. cit., p. 57-59). MACEDO, op. cit, p. 25.

Cláudio Cledson Novaes, Fernanda Aguiar C. Martins, Roberto H. Seidel (Org.) 
do agraciado; pouco importa o homem; mas a casa, a indústria já tem quatro condecorações nobiliárias ${ }^{12}$.

Quando Macedo apontou sua luneta histriônica sobre a capital do Império, em 1868, as marcas da Guerra do Paraguai se faziam sentir em toda parte, inclusive nos produtos confeccionados pelo comerciante. Reis, em 1865, incentivado pela demanda de tecnologia bélica, confeccionou em suas oficinas alças de miras, objetos utilizados em artilharia, que foram oferecidas ao Imperador e testados na fortaleza de São João, em 26 de setembro de 1866, com a presença de várias autoridades militares. Até o fim da guerra, outros instrumentos e artefatos seriam desenvolvidos para o exército, como eclímetro de prumo, agulhas de bitáculas para navios de ferros, o que, possivelmente, ajudou os armazéns a prosperarem ${ }^{13}$. No entanto, a maioria da produção do estabelecimento era de inofensivos instrumentos científicos, como mostra o catálogo publicado em 1865, no qual são apresentados 831 itens, como óculos, agulhas diversas e de diversos tamanhos para navios, recipiente para realização de misturas químicas; ampulhetas; anemômetro; aparelhos diversos para realização de medição e de experiências físicas; barômetros com armações diversas; bússolas; lentes convergentes e divergentes; lentes para relojoeiro, para botânico e oculista; lunetas; pince-nez; telescópios para observações celestes e terrestres; e, como indica o Almanaque Laemmert, "fantasmagorias"14.

12 Idem, p. 24. José Maria dos Reis contava com a proteção do Imperador D. Pedro II, sendo inclusive condecorado, em 1867, com a Ordem de Cristo pelos serviços prestados ao programa da indústria no país. Participou ativamente da Sociedade Auxiliadora da Indústria Nacional (SAIN), instituição fundada em 1816 pelo negociante e proprietário Inácio Álvares Pinto de Almeida, para incentivar a promoção da indústria, do trabalho e da educação no Brasil. Reis foi diversas vezes, na década de 1860, eleito para o Conselho Administrativo da SAIN, fazendo parte da seção de artes liberais e mecânicas. Também foi membro da "Sociedade Reunião dos Expositores da Indústria Nacional", bem como de associações assistenciais como a Benemérita Sociedade Portuguesa, dentre outras (FILHO, op. cit., p. 32-57).

13

"A modalidade de instrumentos fabricados pelas oficinas mantinha uma relação com as atividades que se desenvolviam no Brasil naquele momento. Estas se voltavam para o levantamento de dados geo-físicos, para a demarcação de estradas e de ferrovias, além das operações navais em que a marinha brasileira se via envolvida na região da Prata. As hostilidades que se iniciaram, nesta área, no início da década de 50, prosseguiam agora com a Guerra do Paraguai (1864-70)" (FILHO, op. cit., p. 21-31).

116 Número temático: literatura e cinema. A Cor das Letras - UEFS, n. 11, 2010 
Embora o tipo de invenção ótica não venha especificado, atrás do termo "fantasmagoria"15 escondia-se uma série de projetores de imagens com as mais variadas características. Desde lanternas mágicas, espécie de retroprojetores de madeira ou folha de flandres, até cosmoramas, caixas óticas nas quais os transeuntes do período, após pagarem alguns cobres, admiravam vistas desbotadas, mal iluminadas por tocos de velas e distorcidas por lentes esfumadas - mas ainda assim encantadoras.

Conhecer a história desses inventos é ir além de denominações que os incluem apenas como um capítulo excêntrico na história do cinema. Vivia-se então um momento em que a tecnologia, tornada lúdica pelo entretenimento, começava a fazer parte do cotidiano das metrópoles ditas "civilizadas". O século XIX não se acanhava em disponibilizar a consumidores, por esta época mais incrédulos do que ávidos, prodígios que ficavam a meio caminho entre a ciência e o espetáculo. Reis era apenas mais um entre inúmeros comerciantes que então ofereciam ilusões óticas como agradáveis - e rentáveis - divertimentos familiares.

Em 1856, tem-se notícia da casa de João José de Faria \& Irmão, na rua do Ouvidor, 79, a venda de Polyorama, panopticos e diagraphos, "com as vistas dos principais monumentos da Europa, e as batalhas da Criméia", etc. $^{16}$. Neste mesmo ano, na rua da Alfândega, Agostinho de Souza Neves $e$ C., além de "Luneta de um e dois vidros, óculos para teatro de tartaruga, madrepérola, marfim, porcelana, búfalo e metal", fazia instrumentos para uso de "fantasmagoria"17. O número destes estabelecimentos foi bastante expressivo durante o período, provendo continuamente o interesse do homem do oitocentos pelas novidades óticas.

No livro de memórias O Rio de Janeiro Imperial, de Adolfo Morales de Los Rios, publicado em 1945, talvez a primeira reminiscência brasileira desses projetores produzida no século XX, pode-se acessar um pequeno e significativo verbete sobre o qual estudiosos se debruçaram para entender a

15 Denominação de um novo gênero de espetáculo criado pela conjunção de trabalhos tanto de cientistas como de mágicos, o fantascópio, projetor das afamadas fantasmagorias, surgiu em Paris no final do século XVIII. Com uma adaptação simples e engenhosa, suspendeu-se a lanterna mágica, projetor rudimentar do período, sobre rodas, dando movimento às imagens projetadas na superfície de telas ou vapores, que cresciam e decresciam diante dos olhos do público (MANONNI, Laurent. A grande arte da luz e da sombra - arqueologia do cinema. São Paulo: Senac/Unesp, 2003).

Almanak Laemmert, 1856, p. 563.

17 Almanak Laemmert, 1855, p. 564.

Cláudio Cledson Novaes, Fernanda Aguiar C. Martins, Roberto H. Seidel (Org.) 
realidade ótica brasileira antes do cinematógrafo. O valioso comentário diz o seguinte:

Das coisas que provocaram grande curiosidade devem ser citadas o cosmorama da Rua do Ouvidor, canto das ruas dos Latoeiros, de propriedade de um espanhol exilado político. Essa casa de ilusionismo obteve, durante mais de 3 lustros, o mais retumbante êxito. Por sua vez, as Fantasmagorias de Robertson, ou seja, o planetário instalado na mesma rua, de número 123 , divertia a população das sete às nove horas da noite, com eclipses, o sistema Solar, os planetas, as fases da lua e, também, com objetos medonhos que cresciam e diminuíam produzindo estranhas sensações ${ }^{18}$.

Atraídos por inúmeras novidades científicas, as personagens, tanto da crônica de Ao correr da pena quanto do romance A luneta mágica, expressavam esta curiosidade arrepiante pelos objetos óticos no período. Simplício foi praticamente arrastado para lá pelo velho Nunes; o narrador de Alencar também encontrou no caminho um amigo que o acompanhou até o mítico comércio de José Maria dos Reis. Lá chegando, foram recebidos "com amabilidade e cortesia" pelo proprietário em pessoa, que apresentou sua obra:

Com efeito, não eram exagerados os elogios que me tinham feito dessa casa, onde se encontra um sortimento completo de instrumentos e objetos de óptica, tudo perfeito e bem acabado.

Vi um telescópio que me asseguraram ser o melhor que existe no Rio de Janeiro atualmente, e com o auxílio do qual pode um homem uma bela noite ir fazer uma visita aos planetas e examinar de perto os anéis de Saturno.

Vi muitos outros instrumentos para medir as distâncias, tomar as alturas das montanhas, estudar as variações da atmosfera, muita coisa enfim que os nossos avós teriam de certo classificado como bruxaria ${ }^{19}$.

Aqui, pela primeira vez, vemos surgir entre as palavras de Alencar as inquietantes interseções entre ciência e mágica, um pouco atenuadas pelo escritor responsabilizá-las à incredulidade de uma geração anterior, desacostumada com os milagres da ciência, para a qual as propriedades dos instrumentos do armazém seriam interpretadas como "bruxaria".

Macedo, ao contrário de seu predecessor, não foi nada econômico nas analogias desse tipo, nem se poupou em expressar diretamente os encantos realizados pela ciência através da incredulidade de seus persona-

18 MORALES DE LOS RIOS, Adolfo. O Rio de Janeiro Imperial. Rio de Janeiro: Ed. Top Books, 2000, p. 365.

19 ALENCAR, op. cit., p. 207.

118 Número temático: literatura e cinema. A Cor das Letras - UEFS, n. 11, 2010 
gens. Ainda a caminho das oficinas, Simplício faria a emblemática pergunta ao velho Nunes:

- Mas então o Reis o que é? É mágico?...

- Não sei; suponha que seja o diabo; o certo é que ele tem, e isso é o que mais lhe importa, o segredo de dar vista de águia aos míopes mais infelizes, aos míopes quase cegos ${ }^{20}$.

Assim que chegaram ao seu destino, os dois atestaram a longeva simpatia do proprietário, que também os recebeu pessoalmente de forma amável e atenciosa. Imediatamente, ao tomar conhecimento da intensa miopia de seu cliente, mediu "as proporções" do problema, começando o ensaio "das mais fortes lunetas de vidro côncavo", sem obter nenhum resultado visível. Nem a luneta da força "número dois" foi capaz de fazer com que Simplício enxergasse um palmo diante do nariz. Confirmada a incompetência do afamado Reis em minimizar seus males, o enfermo não conseguiu esconder sua decepção. Mesmo depois do comerciante expor as limitações da ciência, percebemos o triste suspiro do míope Simplício assim se dirigindo ao interessado Reis:

- Ah! É que o meu amigo chegou a fazer-me acreditar que o senhor era mais do que um simples homem, era uma espécie de ente sobrenatural, um mago, um realizador de impossíveis, principalmente em matéria de instrumentos óticos.

- O seu amigo, que é também meu, exagerou muito as minhas pobres condições; eu não creio na magia; mas se lhe apraz consultar um pretendido mágico, é coisa fácil.

- Como?...

- Mandei contratar na Europa um artista de merecimento superior para os trabalhos das minhas oficinas e chegou-me no último paquete um armênio de habilidade extraordinária; mas que me desagrada por ter pretensões a muito sabido em magia ${ }^{21}$.

A dubiedade do posicionamento de Reis quanto à magia fica evidente aqui. Considerava as incursões obscurantistas de seu empregado perigosas à sociedade, "ofensiva à religião, capaz até de perturbar a ordem pública". Apesar de não acreditar pessoalmente nos recursos mágicos, e referendar seu repúdio à prática, recomendava-a aos clientes e tinha em seu corpo de funcionários um com poderes sobrenaturais. Por mais que ele justificasse a presença do "maldito armênio" pela excelência de seu trabalho, guardava 
com o feiticeiro afinidades inconfessáveis, acolhendo-o num gabinete localizado nos fundos de suas oficinas.

Obviamente, deve-se levar em conta que o que temos em mãos é uma ficção com ares de crônica. O verdadeiro Reis empregava, sobretudo, patrícios. Em 1866, em suas oficinas trabalhavam 16 artistas: oito portugueses, sete brasileiros e um italiano, divididos entre as oficinas de ótica, de instrumentos científicos e de marcenaria ${ }^{22}$. O armênio ficou por conta da imaginação de Macedo, sendo elemento de importância fundamental para que se entenda um pouco como foi representado o "empresário" da ciência. O mago da Armênia, de certa forma, funcionava como um "duplo" do comerciante de invenções óticas.

Era um homem alto, magro e com os ossos muito salientes; trazia os cabelos crescidos, o rosto contraído, a face macilenta enegrecida pela fumaça; suas mãos enormes estavam empoeiradas, e seus dedos coroados por grandes unhas que pareciam garras; vestia calças e blusa de pano vermelho ${ }^{23}$.

Nenhum dos visitantes se atreveu a falar na presença de tão mefistofélica criatura. O próprio Reis foi que expôs a infelicidade de seu cliente e as esperanças que o mesmo nutria nos poderes do armênio. Este, alegando ser o sábado um dia em que "os gênios sinistros predominam", prometeu a Simplício que se ele voltasse à meia noite não só teria a vista devolvida, como "a mais penetrante do que desejas e pensas", confeccionando para si uma luneta mágica ${ }^{24}$.

$\mathrm{Na}$ crônica de Alencar, o surgimento do objeto independeu do firmamento de um pacto infernal, que mais tarde traria consequências funestas. O narrador de Ao correr da pena, depois de admirar alguns dos engenhos produzidos no armazém, chegou finalmente aos óculos, e entre "todos aqueles primores d'arte, no meio de tantos trabalhos delicados e tantas invenções admiráveis", chamou-lhe a atenção "uma velha luneta de grossos aros de tartaruga, de feitio tão grosseiro que me pareceu ser uma das primeiras obras do inventor dos óculos" ${ }^{\prime 25}$.

Estava metida numa caixa de marroquim roxo, sobre a qual se destacavam uns traços apagados, que me pareciam de letras desconhecidas de alguma língua antiga.

\footnotetext{
22 FILHO, op. cit., p. 9.

23 MACEDO, op. cit., p. 29.

24 Idem, p. 30-31.

25 ALENCAR, op. cit., p. 208.
}

120 Número temático: literatura e cinema. A Cor das Letras - UEFS, n. 11, 2010 
Disse-me o proprietário que esta luneta Ihe viera por acaso entre uma coleção de elegantes pince-nez que Ihe chegara ultimamente da Europa; excedia o número da fatura, o que fazia supor que naturalmente tinha-se confundido com as outras, quando o fabricante as arrumara numa caixa ${ }^{26}$.

A ausência explicitada de um estrangeiro na primeira versão, no entanto, pouco serviu para mascarar o olhar curioso e amedrontado do homem do oitocentos sobre os exóticos objetos, em sua maior parte, com tecnologia importada, disponibilizados na cidade, manejados pela ciência de italianos, espanhois, americanos, alemães, como artefatos mágicos. Para ilustrar um pouco desse aspecto devemos voltar uma vez mais A luneta mágica. Talvez essas idas e vindas tenham feito se perder um pouco da autonomia de cada obra, fundindo-as numa única, ou confundindo o reflexo de uma sobre a outra. Ambas gozaram diretamente da atmosfera feérica na qual a Corte estava imersa, cindida entre uma recepção pragmática da ciência e outra lúdica, aparatosa e espetacular. Mas, tanto para o bem quanto para o mal, Macedo foi o mais prolixo e extremoso na criação de estranhamentos, como veremos a seguir.

Quando Simplício e o velho voltaram à meia noite ao armazém, conforme o combinado com o bruxo, encontraram um Reis disposto, que logo os encaminhou para o gabinete dos fundos da loja. Trêmulos e amedrontados, ouviram do comerciante a seguinte frase, que em nada ajudou a dissipar a expectativa de presenciarem as mais terríveis visões:

- Isto não passa de uma comédia, que nos fará rir amanhã: a verdadeira magia está nas maravilhosas realidades das ciências físicas ${ }^{27}$.

Chegaram ao fim do corredor. Antes que o Reis batesse na porta, ela se abriu como por encanto, assustando a todos. Em seguida, sem trânsito, foram inseridos no gabinete do sinistro personagem:

O gabinete do armênio estava todo pintado de negro, tendo em branco os caracteres especiais de todos os dias da lua marcados pelas vinte e duas chaves do tarot e pelos sinais dos sete planetas; no meio do teto, também negro, via-se a figura do pentagrama em vermelho vivíssimo ${ }^{28}$.

Mais adiante se descreve os objetos de magia:

Sobre o altar maldito descansavam os instrumentos da magia e entre outros a vara mágica, a espada, a taça e a lâmpada; a um lado, no chão, estava a trí-

\footnotetext{
26 ALENCAR, op. cit., p. 208.

27 MACEDO, op. cit., p. 33.

28 Idem, p. 34.
}

Cláudio Cledson Novaes, Fernanda Aguiar C. Martins, Roberto H. Seidel (Org.) 
pode. Globos, triângulos, a figura do diabo, a estrela de seis raios, os abracadabras, as combinações do triângulo, e uma infinidade de símbolos enchiam a mesa e o gabinete ${ }^{29}$.

A sala do armênio lembrava muito o afetamento místico de uma chamada para sessão de fantasmagoria. No diário parisiense Lês Affiches, publicado em 6 de dezembro de 1792, publicou-se um reclame publicitário de uma destas apresentações nos seguintes termos:

PHANTASMAGORIA, aparição de espectros e invocação das sombras de pessoas celebres, tal como as realizam os rosa-cruzes, os iluminados de Berlim, os teósofos e os martinistas. Os que desejarem ser testemunhas destas invocações tenham a vontade de se apresentar a Paul Filidort, à rue de Richelieu, Hotel de Chartes, n 31. Ele realizará essas invocações duas vezes ao dia, a primeira às cinco horas e meia da tarde, e a segunda às nove horas, à saída dos espetáculos. $O$ preço do ingresso é 3 livres. Ele previne aos cidadãos que estas operações não têm qualquer influência perigosa sobre os órgãos, qualquer odor nocivo, e que as pessoas de todas as idades e sexos podem assistilas convenientemente ${ }^{30}$.

Segundo um cronista, presente na estreia da sessão, apagada a luz:

Um ponto luminoso atravessa a distância da noite profunda; brilha, prende vossos olhares; logo se move, aproxima-se, agiganta-se ao mesmo tempo e toma uma configuração que se define e torna-se mais distinta a cada passo que dá, até que, a quatro ou cinco pés de distância, esse ponto imperceptível vos apresenta o fantasma ainda luminoso de Mirabeau ${ }^{31}$.

Lendo A luneta mágica, é quase impossível não se deixar levar por essa atmosfera e, involuntariamente, repensar as fantasmagorias óticas como parceiras neste jogo onde a razão humana acabava como perdedora impassível. A sessão do armênio é descrita nos seguintes termos:

No fim de alguns minutos a lâmpada mágica lançou e manteve uma tênue flama que começou pálida e fraca, pouco e pouco foi se tornando tensa e rubra, e da qual o armênio retirou a ponta da espada, que pareceu tê-la acendido.

Em seguida ouvimo-lo exorcizar em latim os espíritos elementares, e falar e evocar as ondinas, as salamandras, os silfos e os gnomos; empregou assim

\footnotetext{
29 Idem, p. 34

30 MANONNI, op. cit., p. 156.

31 Idem, p. 158.
}

122 Número temático: literatura e cinema. A Cor das Letras - UEFS, n. 11, 2010 
meia hora pelo menos a entender-se com invisíveis e duvidosos ou quiméricos seres ${ }^{32}$.

Depois de uma série de palavras mágicas, luzes misteriosas e salamandras incandescentes, finalmente a luneta mágica ficou pronta. Com ela nas mãos, o armênio completou:

- Esta luneta é a maravilha da magia: por ela verás demais no presente, e poderias ler no futuro; mas o teu coração é bom, e a tua alma é pura, criança; além do número de três minutos está a visão do mal, que o meu poder de mágico não te pode impedir; porque a visão do mal é a vingança da salamandra escrava; mas a fixidade nesta luneta além do número de treze minutos é a vidência do futuro, e essa eu ta impeço, Cashiel! Schaltiel! Alphiel! Zarabiel! Eu tá impeço, criança louca: essa luneta fixada além de treze minutos se quebrará em suas mãos! ?3 $^{33}$

De posse da lente mesmerizada, Simplício esperou o outro dia para testar as visões maléficas de sua luneta. Foi dormir excitado com esta possibilidade. Acordou estremecido pelo canto dos passarinhos, demorando-se um pouco sobre a cama, vendo emoldurado na janela um dia esplêndido. Foi aí que ergueu a mão convulsa e fixou a luneta mais de dez minutos na paisagem:

Vi o sol, mas não senti nem a luz da majestade, nem o calor que fecunda, vi os raios de ardor e desastroso que crestam as plantas e preparam a miséria e a fome; vi raios que pela insolação tinham de produzir a loucura, vi raios que forjados para vibrar sobre os tanques de águas estagnadas, e sobre os pauís, iam levantar, espalhar fantasmas e com eles derramar a peste e a morte sobre os homens, vi o sol - não formoso - mas cheio de manchas; vi o sol não fonte de vida - mas senti sua força atrativa forjando só os terremotos, os cataclismos, o horror ${ }^{34}$.

A partir de então, Simplício direcionará sua luneta em tudo quanto existe, descortinando um mundo sombrio, no qual as aparências mais prosaicas e banais escondiam projetos de grandiosa maldade, enredando-o na perversidade de um olhar mediado, ampliado pelo engenho humano. Seus familiares tiveram as mentes defasadas e os pecados mais inconfessáveis absorvidos na mirada mágica. Sua prima Anica foi revelada como uma "muIher, fria, egoísta, positiva material"; seu irmão, Américo, teve suas intenções patrióticas vistas como uma alavanca que o levantaria até as altas tri-

\footnotetext{
32 MACEDO, op. cit., p. 35.

33

34

Idem, p. 38.

Idem, p. 43.
}

Cláudio Cledson Novaes, Fernanda Aguiar C. Martins, Roberto H. Seidel (Org.) 
bunas políticas; sua tia Domingas não conseguiu esconder a inveja, a usura, a difamação da vida alheia, o que a tornava uma caricatura repugnante diante do sensível sobrinho.

Todorov, no estudo clássico sobre o fantástico, dedicou alguns parágrafos à análise da obra do contista romântico alemão E. T. A. Hoffmann, $A$ princesa Brambilla, na qual óculos e espelhos foram utilizados para dar acesso ao mundo maravilhoso. Tal como em $A$ luneta mágica, o tema da história é a divisão de personalidade, o desdobramento, o jogo entre o sonho e real, espírito e matéria, que a intermediação destes objetos produziram na consciência de seus protagonistas. Em Hoffmann proliferam microscópios, lunetas, binóculos acercando-se do olhar humano, potencializandoo de uma força encantatória ${ }^{35}$. Max Milner, também atraído pela magia dos contos do escritor alemão, observou, entretanto, que ele não fora o único a se utilizar deste recurso. Segundo o autor:

todos os românticos alemães meditaram, num momento ou noutro, sobre esses aparelhos, que por suas miragens duplicam o aspecto ilusório do mundo, ou que, ao contrário, proporcionam ao olho humano (mas pode ser que se trate de uma ilusão de segundo grau) o sentimento de penetrar no coração íntimo das coisas, ou de participar da luz incriada ${ }^{36}$.

Assim como Simplício, de A luneta mágica, o narrador criado por Alencar em Ao correr da pena igualmente soube bem externar os contínuos embates imaginários entre o olho e a superfície polida de lentes côncavas e convexas. De poder da luneta, ele a direcionou ao companheiro e leu em sua boca, "em letras encarnadas", seu descontentamento de estar ao lado de um "maçante", que o fazia perder tempo. Quando se voltou para Reis, o proprietário, viu "a tradução de um sorriso complacente", e a vontade de que comprasse logo aquele objeto imprestável. Por uma bagatela, o cronista adquiriu a mercadoria, saindo às ruas satisfeito com a aquisição que lhe conferiu o poder de observar o teatro do mundo:

Pensem que turbilhão de idéias, que torvelinho de pensamentos, me agitava a mente exaltada por este fato. Visões fantásticas surgiam de repente e começavam a dançar um sabbat vertiginoso no meu cérebro ensandecido ${ }^{37}$.

35 TODOROV, Tzevetan. Introdução à literatura fantástica. São Paulo: Perspectiva, 1975, p. 129.

36 MILNER, Max. Metáforas e metamorfoses no imaginário científico: o exemplo da ótica. In: VIERNE, op cit, p. 28-29.

37 ALENCAR, op. cit., p. 208-209.

124 Número temático: literatura e cinema. A Cor das Letras - UEFS, n. 11, 2010 
Os dois folhetins brasileiros surgiram perfeitamente integrados às inquietações de seu tempo, observando as cada vez mais cotidianas interferências óticas no interior da Corte. Interessante perceber como, especialmente em Simplício, esses dilemas são febrilmente sentidos em suas ações impulsivas, escravas de uma vontade intermitente em penetrar as aparências, que o levava, assim que vencia o medo e vislumbrava o mal, a experimentar a culpa pela utilização de um aparato demoníaco.

O final da primeira parte de Ao correr da pena apresentou um narrador totalmente seduzido pelas possibilidades abertas pelo objeto mágico, já que, em sua avaliação, a luneta tornou o seu folhetim "um agradável passeio, um doce espaciar, olhando à direita e à esquerda, medindo a calçada a passos lentos, e rindo-me das coisas engraçadas que me revelaria a minha luneta" ${ }^{38}$. Mas, apesar do leve piscar descontraído que Alencar imprime ao seu folhetim - em contraposição às insustentáveis angústias de Simplício - , as invenções óticas também estiveram ali como experimentos desrealizantes, inquietantes, fantásticos. Esta mística bufa das imagens mediadas, projetadas em telas ou simplesmente visualizadas através de lentes disformes, chegaria até a origem do cinema onde a percepção cindida entre uma representação fiel do real e uma manipulação mágica de suas partes produziu tanto os primeiros documentários dos irmãos Lumière como os delírios visuais de Meliès. Concílio nada assustador quando se observa as graças encantatórias da ciência, seus entretenimentos, que o século XIX ainda descobria no assombro de luzes fantasmagóricas.

\section{REFERÊNCIAS}

ALENCAR, José de. Ao correr da pena. São Paulo: Melhoramentos, 1955.

FILHO, Almir Pita Freitas. As officinas e armazém d'óptica e istrumentos scientíficos de José Maria Reis e José Hermida Pazos(Negociantes, ilustrados e utilitários em prol do desenvolvimento da ciência no Brasil). Rio de Janeiro: Museu do Observatório Nacional/CNPq, 1986.

MACEDO, Joaquim Manuel de. A luneta mágica. São Paulo: L\&PM Pocket, 2001.

MANONNI, Laurent. A grande arte da luz e da sombra - arqueologia do cinema. São Paulo: Senac/Unesp, 2003.

MILNER, Max. Metáforas e metamorfoses no imaginário científico: o exemplo da ótica. In: VIERNE, Simone. A ciência e o imaginário. Brasília: Universidade de Brasília, 1994.

MORALES DE LOS RIOS, Adolfo. O Rio de Janeiro Imperial. Rio de Janeiro: Ed. Top Books, 2000.

38 ALENCAR, op. cit., p. 209.

Cláudio Cledson Novaes, Fernanda Aguiar C. Martins, Roberto H. Seidel (Org.) 
TODOROV, Tzevetan. Introdução à literatura fantástica. São Paulo: Perspectiva, 1975. ZALUAR, Augusto Emílio. Doutor Benignus. Rio de Janeiro: Ed. UFRJ, 1994.

\section{Revistas}

Almanak Laemmert, 1854.

Almanak Laemmert, 1855.

Almanak Laemmert, 1856.

126 Número temático: literatura e cinema. A Cor das Letras - UEFS, n. 11, 2010 